\title{
Uma cena para a perda: vergonha e melancolia
}

\author{
A Scene to the Loss: \\ Shame and Melancholy
}

\section{Suely Aires}

Universidade Federal da Bahia [UFBA]

\section{RESUMO}

O presente artigo visa discutir a ausência de vergonha na melancolia e a satisfação dos pacientes em comunicar o desprezo por si mesmo, tal como descritos por Freud em 1917. Para tanto, segue a argumentação do ensaio Luto e Melancolia e indica os aportes conceituais necessários para a apresentação da melancolia como uma neurose narcísica, distinta da vivência de luto. Considerando que a vergonha é um afeto que se coloca na fronteira entre psíquico e social, busca refletir sobre as implicaçôes clínicas de sua ausência na melancolia.

\section{PALAVRAS-CHAVE}

Vergonha; Perda; Luto; Melancolia.

\section{ABSTRACT}

The present article aims to discuss the absence of shame in melancholy and the satisfaction of patients in communicating selfcontempt, as described by Freud in I9I7. To this purpose, it follows the arguments of the essay Mourning and Melancholy and indicates the necessary conceptual contributions for the presentation of melancholy as a narcissistic neurosis, distinct from the experience of mourning. Considering that shame is an affect that stands on the border between psychic and social, we seek to reflect on the clinical implications of its absence in melancholy.

\section{KEY WORDS}

Shame; Loss; Mourning; Melancholy. 
Dai palavras à dor: a tristeza quando não fala, murmura no coração que não suporta mais até que o quebra.

Shakespeare, Macbeth (I6II)

Em Luto e Melancolia (I9I7 [20II]) Freud aborda a melancolia a partir da vivência do luto, estabelecendo uma analogia entre a afecçáo psíquica e o afeto normal de tristeza. Embora considere que a melancolia tem uma definição conceitual oscilante no campo da psiquiatria $^{1}$, Freud se esforça por precisar seus mecanismos psíquicos e destaca os casos que não têm proximidade com afecçôes somáticas. Parece-nos relevante destacar esse aspecto a fim de indicar que o recurso freudiano ao luto, como modelo normal de uma afecção patológica, busca ofertar certa racionalidade a alguns quadros de melancolia — e Freud é cauteloso ao indicar que há a possibilidade de haver elementos orgânicos em determinados casos, em especial quando se encontra alternância entre mania e melancolia - e possibilita articular a melancolia não apenas com o afeto do luto, mas também com a manifestação social relacionada à vivência de perda. ${ }^{2}$ É nesse contexto que buscaremos discutir a expressão da vergonha em sua relação com a melancolia.

\section{Luto e melancolia: limites de uma analogia}

Inicialmente, em seu ensaio, Freud apresenta ao leitor uma definição de luto ${ }^{3}$ e considera seu caráter temporário e não patológico, construindo uma base comum para oferecer uma descrição da melancolia.

A melancolia se caracteriza por um desânimo profundamente doloroso, uma suspensão de interesse pelo mundo externo, perda da capacidade de amar, inibição de toda atividade e um rebaixamento do sentimento de autoestima, que se expressa em autorrecriminações e autoinsultos, chegando até a expectativa delirante de punição (Freud, I9I7 [201I, p. 47]).

É interessante destacar que o autor busca situar a melancolia, a despeito da oscilação conceitual no campo da psiquiatria, por meio de referências ao luto. A recorrência do prefixo Selbst (referente a si mesmo, geralmente traduzido nas expressóes freudianas por auto) dá o tom do que virá a ser apresentado posteriormente: um movimento de retorno à própria pessoa - fundamental para pensar os mecanismos psíquicos em jogo na melancolia - e a colocação em um tempo verbal apassivador, constituindo uma voz

I Para uma discussão sobre o tema, cf. Peres, U. T. Dúvida melancólica, dívida melancólica, vida melancólica (1996).

2 "O termo alemão Trauer [...] pode significar tanto o afeto da dor como sua manifestação externa" (Carone, 20II, p. 44).

3 "[...] via de regra, é a reação à perda de uma pessoa querida ou de uma abstração que esteja no lugar dela" (Freud, I9I7 [2011, p. 47]). 
que não pode se afirmar como ativa e que mantém certa reflexividade. Ou seja, não se trata de uma transformação radical da voz ativa na voz passiva, mas passagem para a voz reflexiva média, construída em uma relação temporal. É justamente a perturbação do sentimento de autoestima que servirá de diferencial entre a melancolia e o luto, no primeiro dos usos do prefixo Selbst.

O trabalho de luto [Trauerarbeit], segundo Freud, caracteriza-se pela retirada da libido do objeto náo mais existente e seu posterior investimento em um objeto substitutivo, em um processo longo e doloroso que, ao chegar a seu fim, permitirá a liberação de um quantum de energia psíquica. Durante o processo de luto, o objeto ausente permanece investido, o que lhe garante presença no mundo psíquico - sonhos, memórias e fantasias - e a realidade sofre desinvestimento libidinal. A melancolia, por sua vez, mantém-se fora do tempo, não se constitui propriamente como um processo e guarda semelhança relativa com o luto. Os pontos de semelhança dizem respeito ao desânimo, à perda de interesse pelo mundo externo e à inibição de atividade, o que inclui a impossibilidade de amar. A diferença coloca-se em relação ao objeto: conhecido no luto e desconhecido, a nível consciente, na melancolia, o que o leva a questionar a relação estabelecida entre sujeito, mundo externo e objeto perdido.

Ao supor que a perda do objeto no luto se dá por subtração de algo ou alguém especial, cuja natureza é conhecida, o sujeito enlutado desinveste do mundo porque este não inclui o objeto de seu interesse. Desse modo, prefere a vida psíquica em que o objeto permanece ao alcance do pensamento - sonho, fantasia ou memória ao menos durante o período de elaboração do luto. Mas, como nos lembra o próprio Freud, "o homem não abandona de bom grado uma posição da libido, nem mesmo quando um substituto já se lhe acena” (Freud, I9I7 [20II, p. 49]). É necessário um longo processo que demanda tempo e energia e, ao longo desse decurso, o eu mantém em seu horizonte a existência do objeto, que não se apresenta propriamente como perdido. A prova de realidade será o procedimento que permitirá ao eu escolher a vida e deixar para trás o objeto, reconhecido como morto.

O melancólico desconsidera a prova de realidade e mantém seu investimento no objeto. Suas críticas não se dirigem ao mundo, mas revelam um empobrecimento do eu por meio das autocensuras e autorrecriminaçóes. "Não julga que lhe aconteceu uma mudança, mas estende sua autocrítica ao passado: afirma que ele nunca foi melhor" (ibid., p. 53). Embora Freud não se detenha nesse aspecto clínico, a dimensão temporal da melancolia é um ponto interessante a ser pensado: essa extensão temporal - sempre fui assim e, de certo modo, sempre serei - pressupóe certa estabilidade desse eu, independente das condiçôes do mundo externo. Não se trata, portanto, de supor que parte de seu comportamento é justificado ou que existe alguma correspondência entre sua autoavaliação, sempre negativa, e os olhos do mundo. Trata-se de uma certeza referente a si mesmo, sendo "infrutífero contradizer o doente" (ibid.).

Esse dado clínico leva Freud a considerar que a comparação entre melancolia e luto tem um limite claro, pois deveríamos supor — ao manter a analogia — que a perda se 
dá na relação do sujeito com o objeto, como uma perda do objeto no mundo, mas a fala dos pacientes melancólicos leva a supor que houve uma perda no eu. Há, portanto, uma diferença entre o sujeito em luto e o sujeito melancólico no que diz respeito à relação entre $e u$, mundo externo e objeto perdido.

\section{Eu e objeto: implicações do conceito de narcisismo}

$\mathrm{Na}$ melancolia, ao considerar-se as falas dos pacientes, mostra-se de forma clara a existência de uma instância crítica autônoma que compóe o eu e, ao mesmo tempo, dele se diferencia. De modo resumido, Freud dirá que o quadro clínico da melancolia póe em destaque o desagrado moral com o próprio $e u$, revelando a face dessa instância crítica. Não se trata de um incômodo com a aparência ou uma crítica sobre determinadas características pessoais, mas concerne a um julgamento moral do melancólico sobre si mesmo, sobre seus pensamentos e desejos. Em 1917, Freud nomeia a instância crítica distinta do eu de consciência moral, mas sabemos dos desenvolvimentos posteriores referentes à noção de supereu, ideal do eu e eu ideal (Freud, I923 [20II]) que permitirão discutir os diferentes investimentos da libido e sua relação com as identificações (Freud, I92I [20II]).

No contexto da discussão do ensaio de 1917 , a noção de narcisismo torna-se fundamental, pois colocará em questão o primeiro dualismo pulsional — pulsôes do eu, de autoconservação, versus pulsôes sexuais - e abrirá novas perspectivas clínicas e teóricas ao considerar a possibilidade de investimento sexual no próprio eu (cf. Freud, I9I4 [20Io]). Uma das consequências da introdução do conceito de narcisismo é justamente a diferenciação entre os modos de relação da libido com o eu e com o mundo: de um lado, Freud apresenta o deslocamento da libido, a substituição dos objetos reais por objetos fantasiados, como traço da neurose - e aqui o luto encontra-se mais uma vez como afeto normal e protótipo para pensar a melancolia; de outro lado, Freud indica a recusa da realidade, do mundo externo, e o desligamento ou represamento da libido como específicos dos casos de psicose - e a melancolia, ainda que lembremos de sua oscilação conceitual, aproxima-se fortemente do campo das psicoses, inicialmente nomeadas por Freud como neuroses narcísicas.

A distinção entre os modos de investimento libidinal, no entanto, não é levada ao extremo de se supor uma diferença radical na experiência de luto e na vivência da melancolia. $\mathrm{O}$ modelo comparativo utilizado até entáo para a construção do argumento se sustenta na condição de ressaltar o que insiste como diferença. Freud, mantendo a elegância textual que caracteriza sua escrita, equilibra seu projeto heurístico: o luto ilumina aquilo que podemos compreender sobre a melancolia; e a melancolia, por sua vez, permite reconhecer os traços exagerados e destoantes em relação à vivência psíquica do luto, possibilitando investigar o funcionamento psíquico. Mais do que uma oposição, trata-se de um modo de pensar o psiquismo que permite considerar luto e melancolia - bem como neurose e psicose - por meio de um funcionamento humano comum. 
A noção de investimento libidinal permitirá articular eu e objeto em um processo cujos resultados são variáveis e que deve necessariamente considerar o conceito de narcisismo. O resultado normal de um processo de desinvestimento libidinal do eu sobre o objeto implica o trabalho de elaboração do luto; ou seja, a substituição de um objeto por um novo objeto de amor, após um período de recolhimento. A melancolia segue outro trajeto: revela-se como resultado de um processo em que houve investimento no objeto, mas a retirada de libido, após a morte ou decepção com o objeto de amor, não possibilitou o deslocamento do investimento. A libido não se dirigiu para um outro objeto, tendo se retirado para o $\mathrm{eu}$, produzindo uma identificação do $e u$ com o objeto abandonado: a perda do objeto se transformou em perda do eu (Freud, I9I7 [20II, p. 6I]).

Ao referir-se ao $e u$, Freud afirma que essa instância é construída a partir de experiências externas, enfatizando o papel da identificação. No contexto da melancolia, a perda do objeto se transformou em perda do eu e o conflito entre o eu e objeto de amor tomou a forma de um conflito entre a instância crítica do eu e o $e u$ modificado pela identificação com o objeto. Ou seja, a identificação entre $e u$ e objeto traz como consequência que a crítica do $e u$, que poderia estar voltada para o objeto real no mundo ou para o objeto da fantasia, tal como acontece no luto ${ }^{4}$, volta-se para o próprio eu - movimento reflexivo que se dá a ver no uso recorrente do prefixo Selbst na argumentação freudiana.

A melancolia é efeito de um processo singular que aproxima diferentes operaçóes, mas que necessariamente deve sustentar-se sobre uma base narcísica para a escolha do objeto, respondendo à ambivalência que se institui nessa relação. Nesse processo, o investimento libidinal em direção ao objeto sofre uma inflexão e regride para o eu em função de sua identificação narcísica com o objeto, substituindo o investimento no objeto pela identificação ao objeto. "A identificação narcísica com o objeto se torna então um substituto do investimento amoroso e disso resulta que, apesar do conflito, a relação amorosa com a pessoa amada não precisa ser abandonada" (ibid., p. 63). Nesse argumento, Freud aproxima escolha narcísica de objeto e regressão por meio do conceito de identificação, de modo a caracterizar a melancolia como um processo regressivo que parte da escolha narcísica de objeto para o narcisismo.

Ainda mantendo a aproximação entre luto e melancolia, Freud destaca o papel da ambivalência das relaçôes amorosas na constituição do quadro melancólico, mas busca incluir nesse processo a retração regressiva da libido. Dito de modo claro: para que uma melancolia se constitua é necessário um somatório de elementos para além do que se dá a ver no luto, quais sejam: escolha narcísica (do objeto), ambivalência (frente ao objeto),

4 Embora Freud discorra sobre a ambivalência como característica da melancolia, não indicando tão claramente sua presença nas vivências de luto, ele coloca em discussão, ao fim de seu ensaio, a presença da ambivalência nas recriminaçóes obsessivas depois de casos de morte. Desse modo, pode-se considerar - em consonância com a construção da teoria psicanalítica desde I895 (Freud, I893-I895 [2016]) — que a ambivalência é constitutiva da vida psíquica, estando na base dos conflitos neuróticos. 
identificação narcísica (ao objeto) e, ponto fundamental, regressão ao período do narcisismo. A melancolia implica, portanto, uma retraçáo libidinal que provoca o abandono do objeto e que mantém o amor. No entanto, em função da ambivalência, esse amor é também ódio ao objeto que, ao ser substituído por meio do processo de identificação, conduz às recriminaçóes do melancólico contra si mesmo: esse objeto substitutivo é humilhado e insultado, produzindo satisfação parcial — sádica, dirá Freud's (I9I7 [20II, p. 67]) — por infligir sofrimento ao objeto e ao $\mathrm{eu}$.

De forma categórica, Freud afirmará que as recriminaçóes apresentadas contra o próprio eu podem ser traduzidas em reclamaçôes contra o objeto. Ou seja, um obscurecimento das fronteiras entre externo e interno pode ser suposto e se dá a ver por meio da inadequação entre as acusaçôes feitas pelo sujeito contra si mesmo e a proximidade entre estas mesmas acusaçóes e um objeto de amor. Freud teoriza, a partir da escuta desses pacientes, que as recriminaçóes contra o objeto de amor se voltaram contra o eu. Ao autorrecriminar-se, ao queixar-se, o sujeito acusa e denuncia o objeto de amor. Ihre Klage sind Anklagen. Queixar-se é dar queixa, acusar, prestar queixa contra o outro, no sentido de acusação pública, dirá Carone (20II, p. 58). A publicidade dessa queixa chama a atenção pela ausência do sentimento de vergonha. "Eles não se envergonham, nem se escondem" (Freud, I9I7 [2011, p. 59]).

Freud justifica a ausência de vergonha na melancolia pelo fato de as acusaçóes estarem voltadas contra o outro, náo atingindo propriamente o sujeito, que sequer tem consciência de que se queixa de um outro: todo esse conflito só pode ser pensado como sendo de ordem inconsciente, já que a consciência não apreende senão parte do processo, seu resultado. O recurso freudiano à identificação, como processo constitutivo do eu, permite destacar a base inconsciente que preside a escolha de objeto e sua perda nos casos de melancolia:

Houve uma escolha de objeto, uma ligação da libido a uma pessoa determinada; graças à influência de uma ofensa real ou decepção por parte da pessoa amada, essa relação de objeto ficou abalada. O resultado não foi o normal, uma retirada da libido desse objeto e o seu deslocamento para um novo, mas foi outro [...]. O investimento de objeto provou ser pouco resistente, foi suspenso, mas a libido livre não se deslocou para um outro objeto, e sim se retirou para o ego (Freud, I9I7 [20II, p. 6I]).

O conceito de identificação permitirá a Freud enunciar sua bela fórmula — a sombra do objeto caiu sobre o eu (ibid.) - e indicar que a cisão do eu é condição necessária para que o eu seja julgado por sua identificação ao objeto abandonado no processo de adoecimento melancólico. Caberia perguntar: De que abandono se trata? Quem abandona quem?

5 Nesse ensaio, Freud dedica-se a pensar o sadismo em sua relação com a tendência ao suicídio presente em casos de melancolia. Cabe destacar que a ausência do conceito de pulsão de morte (Freud, I920 [20I0]), desenvolvido apenas em 1920, limita essa discussão. Seria interessante fazer uma confrontação entre os modos de apresentação do suicídio na obra freudiana antes e depois de I920, o que náo é objeto do presente artigo. 
O caráter reflexivo dessa operação faz com que a perda seja vivenciada de forma passiva pelo $e u$, que, no entanto, ativamente a reproduz, maltratando o objeto, recriminando-o, mostrando sua face negativa. É, pois, um eu modificado pela identificação que sofrerá as agruras da agressividade do eu contra o objeto, reflexividade que só se torna possível em função da identificação. A identificação se coloca como prévia à escolha de objeto e se constitui como a primeira modalidade pela qual o eu distingue um objeto, ainda que a expressão da agressividade se mostre ambivalente.

Cabe considerar que Freud parece produzir certa indeterminação na relação entre escolha de objeto e identificação, visto que, de um lado, apresenta a melancolia como um adoecimento psíquico no qual a libido náo se dirigiu para um outro objeto, tendo se retirado para o $e u$, o que produziu uma identificação do $e u$ com o objeto (Freud, 1917 [20II, p. 6I]) e, de outro, argumenta que a identificação se constitui como a primeira modalidade pela qual o eu destaca um objeto (ibid., p. 63). Essa aparente contradição se esclarece quando Freud mantém, lado a lado, a noção de ambivalência e a base narcísica de escolha do objeto. Ou seja, a conclusão freudiana dirige-se para o reconhecimento do predomínio do tipo narcísico de escolha de objeto na disposiçáo para a melancolia, o que produziria essa indeterminação na relação entre escolha de objeto e identificação.

A teorização sobre a identificação só será desenvolvida de forma mais detalhada posteriormente, em I92I, no texto Psicologia das Massas e Análise do Eu (I92I [2011]). No entanto, em I9I7, Freud lança as bases para se pensar a melancolia como um adoecimento do $e$, em seu processo constitutivo, de relaçáo com o objeto. A melancolia, como uma ferida aberta (cf. Peres, 20IO), atrai para si as energias de investimento e esvazia o $e u$, produzindo um empobrecimento radical. Seu processo de elaboração se trama em torno de "inúmeras batalhas isoladas, nas quais ódio e amor combatem entre si: um para desligar a libido do objeto, outro para defender contra o ataque essa posiçáo da libido" (Freud, I9I7 [20II, p. 8I]).

\section{Vergonha e melancolia: uma batalha a céu aberto}

Por que razão a ausência de vergonha chama a atenção de Freud? No argumento freudiano, a distinção entre luto e melancolia é melhor apresentada quando é referida às autorrecriminaçóes, autoacusaçóes e autodepreciação que se destacam nas falas de pacientes melancólicos e que se encontram ausentes na vivência de luto. $\mathrm{O}$ voltar-se contra si mesmo, o uso recorrente do Selbst no texto freudiano, aponta para o movimento reflexivo característico da melancolia e indica a presença da instância crítica como parte do funcionamento do $e u$, que aparece cindido. É como parte desse argumento que Freud chama a atenção para a ausência de vergonha, não sem antes afirmar que esse sujeito parece captar com mais agudeza do que os demais a verdade sobre o homem: mesquinhez, egoísmo, dependência constituem a natureza humana e cada um de nós busca ocultar as fraquezas de seu ser. De certo modo, podemos considerar que aqui se 
antecipa a visão de homem presente em $O$ Mal-estar na civilização (I930 [2010]) ${ }^{6}$, ainda que não haja uma teorização sobre a pulsão de morte.

"Sem dúvida, quem pode chegar a uma tal autoapreciação e expressá-la diante dos outros [...] está doente, quer diga a verdade, quer seja mais ou menos injusto consigo próprio" (Freud, I9I7 [20II, p. 55]). O que chama a atenção de Freud não é propriamente a avaliação feita quanto ao próprio caráter, mas a exposição pública desta apreciação. Parece haver certa permeabilidade entre interno e externo, entre o que se pensa e o que se diz, entre o que se constitui como próprio e como alheio. A vergonha, como afeto, mantém-se nas fronteiras, entre psíquico e social; ou, dito de outro modo, a vergonha como traço de subjetividade, depende da constituiçáo de um espaço de interioridade, velado ao olhar do outro e, ao mesmo tempo, revelado no momento de embaraço.

Para que se produza um efeito de vergonha se faz necessário supor, primeiramente, que o eu tem como referência uma imagem de si e que, em tempo posterior, ele reconheça no olhar do outro sua própria condição de objeto distante dessa representação e, comparativamente com a imagem inicialmente constituída, confirme ou conclua sua perda em relação ao referencial humano, mas que, ainda assim, faça o gesto de se afirmar como homem (cf. Aires, 20I2). Como ameaça de desnudamento, a vergonha indica a condição subjetiva daquele que vivencia a situação de objeto, pois coloca-se como efeito de um reconhecimento entre homens, como marca de humanidade e reduto último do humano: eu e outro, interiorizado, se encontram no sentimento de vergonha.

Nesse sentido, a vergonha permite ao eu experimentar-se como objeto e responder como $\mathrm{eu}$; ou seja, permite ao sujeito experimentar-se como sujeito, ainda que em extrema objetificação, diante do olhar e da avaliação do outro. "A vergonha é desde o início e sempre um sentimento social" (Tisseron, 20I4, p. 3), pois coloca-se na relação com o outro, presença real ou imaginária que condiciona esse afeto (cf. Soler, 20II). Há, no momento do embaraço, subjetivação e dessubjetivação em um tempo preciso, em que eu e imagem se diferenciam e se sobrepóem.

A temporalidade da vergonha, o breve instante de confrontação com o olhar do outro e a conclusão que daí advém (cf. Lacan, 1945 [1998]), se perde na temporalidade monótona da melancolia, um tempo que parece não sofrer variaçôes e que implica certa suspensão da perda. A relaçấo do sujeito com o tempo afigura-se na mesma base das relaçôes com o objeto: o melancólico não sabe o que perdeu, nem quando perdeu — eternidade de uma perda que parece nunca se efetivar por completo. Como nos lembra Freud (I9I7 [20II, p. 63]), o objeto se perde e o amor se mantém; mas também podemos considerar

6 “[...] o ser humano não é uma criatura branda, ávida de amor, que no máximo pode se defender, quando atacado, mas sim que ele deve incluir, entre seus dotes instintuais, também um forte quinhão de agressividade. Em consequência disso, para ele o próximo não constitui apenas um possível colaborador e objeto sexual, mas também uma tentação para satisfazer a tendência à agressão, para explorar seu trabalho sem recompensá-lo, para dele se utilizar sexualmente contra a sua vontade, para usurpar seu patrimônio, para humilhá-lo, para infligir-lhe dor, para torturá-lo e matá-lo" (Freud, I930 [2010, pp. 76-77]). 
que a própria perda se perde, visto que, nesse tempo suspenso da vivência melancólica, o objeto, parte do eu e a perda são mantidos fora da consciência. O caráter indizível e irrepresentável dessa perda impede que o eu reconheça a morte do objeto, tal como ocorre no luto (Freud, I9I7 [20II, p. 83]), bem como impede que o melancólico possa dizer algo sobre isso de forma direta. As acusaçôes mostram esse desvio, são indiretas ao enganar-se em relaçáo ao alvo: não se trata do $e u$ — humilhado, rebaixado e de pouco valor - mas de uma acusaçáo voltada para o objeto.

No contexto clínico da melancolia, a fala do outro parece não importar. Não se trata, portanto, de uma discordância de pontos de vista na avaliação feita pelo interlocutor e pelo melancólico em relaçáo ao seu valor. Nada do que o interlocutor disser que se mostre contrário ao juízo do melancólico sobre si mesmo será considerado — como tão bem indica Freud (I9I7 [20II, p. 53]) —, mas sua observação precisa revela que:

O melancólico não se comporta inteiramente como alguém que faz contrição de remorso e autorrecriminação em condiçóes normais. Falta a ele, ou pelo menos não aparece nele de modo notável, a vergonha perante os outros [...]. No melancólico, quase se poderia destacar o traço oposto, o de uma premente tendência a se comunicar, que encontra satisfação no autodesnudamento (Freud, I9I7 [20II, p. 55]).

Náo se trata apenas da ausência de vergonha, mas destaca-se a satisfação do autodesnudamento, da exposição de si que, segundo o argumento freudiano, dirige-se ao objeto. Esse movimento parece ir de encontro à apreensão narcísica de si, à preservação da própria imagem, como se a melancolia operasse na direção oposta ao narcisismo (Butler, 1997 [2007]). Contudo, a exposição de si alinha-se ao narcisismo em função da relação identificatória constituída entre eu e objeto nos casos de melancolia, em que a escolha de objeto já operou sobre uma base narcísica e em que o eu se constitui como objeto tendo o outro como modelo: o melancólico está no centro da cena, ainda que se veja de fora. De forma especial na melancolia, o eu toma a si mesmo como objeto, para maltratá-lo, humilhá-lo e daí extrair satisfação.

Poderíamos, então, considerar que na melancolia produz-se uma ruptura do laço social? A ausência de vergonha implicaria exclusão radical do outro, da alteridade? Como já destacamos, o espanto de Freud refere-se não apenas à ausência de vergonha, mas à premente tendência a se comunicar. Estranhamente, na melancolia, a exposiçáo de si em sua versão rebaixada pode ser compreendida como modo de relação com o outro, pela insistência em denunciar sua própria inferioridade e, ao mesmo tempo, pode ser vista como ruptura do laço social. A ligação com o mundo parece, de um lado, ser substituída pela relação entre instâncias psíquicas - instância crítica e eu - e, de outro, parece ser mantida por meio das declaraçôes que consideram a possibilidade de que o outro escute seus impropérios.

Retomemos: a ausência de vergonha implica exclusão radical do outro? Há ruptura do laço social? Essas perguntas exigem uma resposta mais delicada, visto que, como linha argumentativa central, Freud detém-se especificamente nos laços libidinais que 
unem eu e objeto, destacando a dimensão de vivência psíquica tanto do luto quanto da melancolia e, nesse contexto, aponta para uma retração da libido e para uma regressáo ao narcisismo. Por outro lado, ao recorrer à noção de identificação para abordar a melancolia, Freud abre a perspectiva de se considerar que a instância crítica do melancólico é uma categoria ao mesmo tempo social e psíquica. Ou seja, a existência da instância crítica já marca a presença da ordem social, em um tempo anterior, constitutivo do eu, que, no momento de adoecimento melancólico, parece estar ausente.

O isolamento dos melancólicos, sua falta de interesse pelo mundo externo, justifica-se pela retração da libido. No entanto, a premência a comunicar seu rebaixamento, a necessidade de apresentar-se inferior aos olhos dos outros, parece implicar uma certa forma de laço, "um desvio que religa a melancolia à sua sociabilidade perdida ou recolhida” (Butler, 1997 [2007, p. I89]). Ora, é o movimento de recusa — silêncio, anorexia e suicídio - que pode, então, ser compreendido como ruptura radical do laço social, do investimento voltado para o mundo externo, que - considerando-se que estamos acompanhando Freud em 1917 - implica a subversão da pulsão que liga o homem à vida (Freud, I9I7 [20II, p. 53]). Ainda assim, Freud destaca a possibilidade de pensar o suicídio em sua relaçáo com o sadismo; ou seja, como uma reversão para o próprio eu da agressividade voltada contra o objeto, uma das vicissitudes da pulsão (id., I9I4 [2013]) que se ancora na proposta do primeiro dualismo pulsional freudiano.

Podemos considerar que a pulsão de morte, que ainda não se deixa enunciar teoricamente, já lança sua sombra na concepção de psiquismo humano de então. Desde i9ı14, em seu artigo sobre o narcisismo, Freud encontra-se às voltas com as deduçóes teóricas e descobertas clínicas que apontam para a necessidade de rever o dualismo pulsional que opóe eu e sexualidade.?

\section{Qual cena para a perda?}

Como constituir uma cena para perda, um enquadramento que possibilite um efeito de conclusão no tempo indefinido da melancolia? O luto, em seus aportes sociais — rituais compartilhados e privados que delimitam certo tempo para a elaboração —, institui uma cena para a perda que goza de reconhecimento social e possibilita a nomeaçáo do vivido. Sem cena para a perda, sem palavras que nomeiem o que se encontra em questáo, a melancolia segue sem bordas precisas, em uma oscilação que não é apenas teórica ou descritiva, mas vivencial. As palavras do melancólico, daquele que vive o adoecimento, não dizem dessa experiência, apenas apontam para o $e u$, para essa vida rebaixada e miserável, indigna de cuidado e dedicação e que, ainda assim, clama por atençáo.

Nesse sentido, não há moldura para a perda na vivência melancólica, há uma grande invasão afetiva que não se deixa enquadrar. No entanto, cabe considerar que "o que não

7 A vergonha não se constitui como tema específico na investigação freudiana. Mesmo na reflexão lacaniana, encontra-se apenas uma única menção à vergonha (Lacan, I969-1970 [1992], p. I72), sendo mais frequente referências ao pudor (cf. Krutzen, 200o). Nesse sentido, torna-se difícil pensar qual o impacto do segundo dualismo pulsional sobre a concepçáo de vergonha na teoria freudiana. 
pode ser declarado pelo melancólico, não obstante, é o que rege a fala do melancólico — uma indizibilidade que organiza o campo do dizível” (Butler, 1997 [20I7, p. 193]). Como se diz o que aí se diz? Talvez a indicação de Freud quanto aos aspectos clínicos da melancolia possa nos servir de guia: ao escutar a fala de seus pacientes, ele conclui que de nada adianta discordar da avaliação que o melancólico faz de si, tanto por se tratar de uma espécie de delírio de inferioridade moral — e como formação delirante mantém uma lógica própria que desconsidera as premissas compartilhadas socialmente - quanto porque "logo teremos que confirmar, sem restrições, algumas de suas afirmaçóes" (Freud, I9I7 [20II, p. 53]).

A atenção às falas dos melancólicos é o que permite a Freud considerar não apenas a ausência do filtro social da vergonha, que deveria implicar certa preservação de sua imagem, mas se deixar surpreender pela constatação da satisfação envolvida na autodepreciação. No manejo clínico proposto por Freud, a escuta das falas do melancólico deve contemplar sua singularidade, o que permite dar valor de verdade ao que é dito pelo paciente, sem, contudo, supor que se trata de uma correspondência entre quem diz o que diz de quem se diz. Como se o procedimento consistisse - em certa similaridade com as operaçôes linguísticas do caso Schreber (id., I9I2 [20I0, p. 83-87]) - em uma reorganização do dito que não implica tradução, mas mudança de direção, de posição e de objeto.

O que o paciente diz é verdadeiro, desde que se atente para o jogo de formulaçóes possíveis: a avaliação depreciativa, em um erro de direçáo, volta-se sobre o próprio $e u$, mas refere-se a um outro; esse outro é objeto de amor; esse outro é objeto de ódio; esse outro é exterior ao $e u$; esse outro é parte do $e u$, por ter sido internalizado; eu e objeto encontram-se identificados; o eu encontra-se cindido. Cada uma das formulaçôes é verdadeira, ainda que pareçam estar em contradição. É a escuta paciente das múltiplas autoacusaçóes do melancólico (id., I9I7 [20II, p. 59]) que possibilita reconhecer a exterioridade das censuras — voltadas para o objeto - e sua introjeção — dirigindo-se ao eu; ou melhor, a uma parte do eu. A intervenção clínica visaria, portanto, a manutenção do laço social por meio da oferta de uma escuta àquilo que o paciente parece falar sem endereçamento, apenas referindo-se a si mesmo. Nesse sentido, o analista se oferece como alteridade, acompanhando o tênue fio das palavras do melancólico. ${ }^{8}$

Do ponto de vista metapsicológico, os argumentos para pensar a melancolia referem-se ao movimento reflexivo da agressividade em direçáo ao $e$, à regressão ao narcisismo, à retração da libido, o que leva a enfatizar os conceitos de narcisismo e identificação. $\mathrm{Na}$ perspectiva freudiana, os achados clínicos relacionados às afecçôes melancólicas permitem o avanço da teoria psicanalítica, em especial no que se refere à compreensão

8 Como indicado anteriormente, a melancolia tem grande variação, podendo inclusive ser pensada no plural: melancolias. Ao me referir a uma posição do analista na escuta do melancólico estou me limitando à direção da cura em psicanálise, o que não exclui o recurso à medicação e o reconhecimento da dimensão química de alguns quadros de adoecimento. Mesmo Freud já aponta a possibilidade da existência de quadros de melancolia de origem tóxica (cf. Freud, I9I7 [20II, p. 73]). 
das relaçóes entre eu e objeto em situações de perda. A ausência de vergonha e a exposição de si são, por sua vez, os pontos que possibilitam a discussão sobre a fronteira entre social e psíquico na composição do eu, pois implicam uma presença do outro, externo ou internalizado, que antecede o quadro de adoecimento psíquico. No entanto, esse é um aspecto pouco explorado, mas que, a nosso ver, coloca-se como baliza clínica.

A cena para a melancolia poderia vir a ser composta a partir do olhar e escuta do analista frente às palavras e ao silêncio do melancólico, que talvez venham a instituir um testemunho sobre a vivência de adoecimento para além de sua nomeação. Ao indicar que se trata de uma melancolia, o analista pode vir a se incluir e, por meio da nomeação, constituir um termo terceiro para o que parece se manter na encenação entre instância crítica e eu; e que teoricamente supomos fazer parte do teatro privado entre eu e objeto. É como elemento terceiro, que um nome para a perda pode advir e um testemunho ${ }^{9}$ (do melancólico) pode ser recolhido (pelo analista): fale, fale tudo o que lhe ocorrer, mesmo que pareça sem importância, mesmo que cause constrangimento ou vergonha. Na melancolia, a ausência de vergonha parece deixar à mostra o que ainda deve ser construído, por meio de uma aposta na palavra.

Há uma saída - falar, falar muito / São as palavras que suportam o mundo, / não os ombros. Sem o "porquê", o "sim", / todos os ombros afundavam juntos. / Basta uma boca aberta / (ou um rabisco num papel) / para salvar o universo (Britto, 2003).

Ao inventar modos de narrar, ao dizer de uma perda que náo se reconhece como tal, o sujeito poderá, talvez, construir um enquadre temporal e enunciativo para a melancolia: tempo para concluir o que pareceu, por um momento, eterno; espaço para construir uma cena singular para a perda na melancolia.

\section{Referências bibliográficas}

Agamben, G. Homo Sacer: o poder soberano e a vida nua I. Tradução de Henrique Burigo. Belo Horizonte: UFMG, 2002.

Aires, S. "Era como se a vergonha devesse lhe sobreviver...". In: De um discurso sem palavras. Nina Leite, J. Guillermo Milán-Ramos. Maria Rita Moraes (org). Campinas, sp: Mercado de Letras, 2012.

Britto, P. H. "De vulgari eloquentia". In: Brito, P. H. Macau. São Paulo: Companhia das Letras, 2003.

Butler, J. (1997). A vida psíquica do poder: teorias da sujeição. Tradução de Rogério Bettoni. Belo Horizonte: Autêntica Editora, 2017.

Freud, S. (I893-1895). "Estudos sobre a histeria". In: Freud, S. Obras Completas, volume 2: Estudos sobre a histeria (I893-I895). Tradução de Laura Barreto. Revisão da tradução: Paulo César de Souza. São Paulo: Companhia das Letras, 2016.

9 Em latim, pode-se usar dois termos para referir-se à testemunha: testis, que diz respeito ao depoimento de uma pessoa em um processo, elemento terceiro; e superstes, o sobrevivente, aquele que vivenciou tal situação (Agamben, 2002). 
(1912). "Observações Psicanalíticas sobre um Caso de Paranoia Relatado em Autobiografia”. In: Freud, S. Obras Completas, volume ro: Observações Psicanalíticas sobre um Caso de Paranoia Relatado em Autobiografia ("o caso Schreber"), Artigos sobre Técnica e Outros Textos (I9II-I9I3). Tradução e notas de Paulo César de Souza. São Paulo: Companhia das Letras, 2010.

(19I4). "Introdução ao narcisismo". In: Freud, S. Obras Completas, volume I2: Introdução ao Narcisismo: ensaios de metapsicologia e outros textos (I9I4-1916). Tradução e notas: Paulo César de Souza. São Paulo: Companhia das Letras, 20 Io.

(1914). As Pulsóes e seus Destinos. Tradução de Pedro Heliodoro Tavares. Edição Bilíngue. Belo Horizonte: Autêntica Editora, 2013.

(I9I7). Luto e melancolia. Tradução de Marilene Carone. São Paulo: Cosac Naify, $20 I I$.

(1920). "Além do princípio do prazer". In: Freud, S. Obras Completas, volume I4: História de uma neurose infantil ("o homem dos lobos"); além do princípio do prazer e outros textos (1917-1920). Tradução de Paulo César de Souza. São Paulo: Companhia das Letras, 2010.

(I92I). "Psicologia das massas e análise do eu". In: Freud, S. Obras Completas, volume I5: Psicologia das massas e análise do eu e outros textos (1920-I923). Tradução de Paulo César de Souza. São Paulo: Companhia das Letras, 2011.

(1923). "O eu e o id". In: Freud, S. Obras Completas, volume i6: O eu e o id, "autobiografia" e outros textos (1923-1925). Tradução de Paulo César de Souza. São Paulo: Companhia das Letras, 201 .

(1930). "O mal-estar na civilização". In: Freud, S. Obras Completas, volume I8: O mal-estar na civilização, novas conferências introdutórias à Psicanálise e outros textos (1930I936). Tradução e notas de Paulo César de Souza. São Paulo: Companhia das Letras, 2010.

Krutzen, H. (2000). Jacques Lacan: séminaire 1952-1980. Index référentiel. Paris: Anthropos.

LaCAN, J. (1945). "O tempo lógico e a asserção de certeza antecipada". In: LaCAN, J. Escritos. Tradução de Vera Ribeiro. Rio de Janeiro: Jorge Zahar, 1998.

(1969-1970). Seminário 17: O Avesso da Psicanálise. Versão Brasileira: Ari Roitman. Rio de Janeiro: Jorge Zahar, 1992.

Peres, U. T. (1996). "Dúvida melancólica, dívida melancólica, vida melancólica". In: Melancolia. Urania Tourinho Peres (org). São Paulo: Escuta.

(20II). "Uma ferida a sangrar-lhe a alma". In: Freud, S. (I9I7). Luto e melancolia. Tradução de Marilene Carone. São Paulo: Cosac Naify.

Shakespeare, W. (2003 [i6ir]). "Macbeth”. In: Shakespeare, W. Tragédias. Sáo Paulo: Nova Cultural.

Simanke, R. (2009). A formação da teoria freudiana das psicoses. São Paulo: Ed. Loyola.

Soler, C. (20II). Les Affects Lacaniens. Paris: puf.

Tisseron, S. (20I4). La honte : psychanalyse d'un lien social. Paris : Dunod. 